\title{
Removal of Selected Pharmaceuticals and Personal Care Products in Wastewater Treatment Plant in Jordan
}

\author{
Othman Al-Mashaqbeh ${ }^{1, *} \oplus$, Diya Alsafadi ${ }^{2}$, Sahar Dalahmeh ${ }^{3}$, Shannon Bartelt-Hunt ${ }^{4}$ and \\ Daniel Snow ${ }^{5}$ (iD \\ 1 Water and Environment Centre, Royal Scientific Society, Amman 11941, Jordan \\ 2 Testing Sector, Royal Scientific Society, Amman 11941, Jordan; DiyaAlhaq.Alsafadi@rss.jo \\ 3 Department of Energy and Technology, Swedish University of Agricultural Sciences, SE 75007 Uppsala, \\ Sweden; sahar.dalahmeh@slu.se \\ 4 College of Engineering, University of Nebraska-Lincoln, Omaha, NE 68588, USA; sbartelt@unl.edu \\ 5 Water Sciences Laboratory, University of Nebraska, Lincoln, NE 68583, USA; dsnow1@unl.edu \\ * Correspondence: othman.mashaqbeh@rss.jo
}

Received: 1 September 2019; Accepted: 19 September 2019; Published: 26 September 2019

\begin{abstract}
The largest wastewater treatment plant in Jordan was monitored in the summer to determine the removal of pharmaceuticals and personal care products (PPCPs). Grab samples were collected from the influent and effluent of As-Samra Wastewater Treatment Plant (WWTP). Liquid chromatography and tandem mass spectrometry (LC-MS/MS) were utilized to determine the concentrations of 18 compounds of pharmaceuticals and personal care products (PPCPs). The results showed that 14 compounds were detected in the collected samples from the influent and effluent of As-Samra WWTP. These compounds are 1,7-dimethylxanthine, amphetamine, acetaminophen, caffeine, carbamazepine, cimetidine, cotinine, diphenhydramine, methylenedioxymethamphetamine (MDMA), morphine, phenazone, sulfamethazine, sulfamethoxazole, thiabendazole, and trimethoprim. However, four compounds were below the detection limit $(<0.005 \mu \mathrm{g} / \mathrm{L})$, namely cimetidine, methylenedioxyamphetamine (MDA), methamphetamine, and sulfachloropyridazine. Among PPCPs, the highest estimated average concentrations in raw wastewater were caffeine, acetaminophen, 1,7-dimethylxanthine, cotinine, and carbamazepine sampled during the summer, at an estimated concentration of $155.6 \mu \mathrm{g} / \mathrm{L}, 36.7 \mu \mathrm{g} / \mathrm{L}, 10.49 \mu \mathrm{g} / \mathrm{L}$, and $1.104 \mu \mathrm{g} / \mathrm{L}$, respectively. However, the highest estimated average concentrations in treated wastewater were for carbamazepine, sulfamethoxazole, caffeine, cotinine, and acetaminophen, at $0.856 \mu \mathrm{g} / \mathrm{L}, 0.096 \mu \mathrm{g} / \mathrm{L}, 0.086 \mu \mathrm{g} / \mathrm{L}, 0.078 \mu \mathrm{g} / \mathrm{L}$, and $0.041 \mu \mathrm{g} / \mathrm{L}$, respectively. In general, the results showed that some compounds in the collected samples of wastewater in Jordan have concentrations exceeding the values reported in the literature. The removal efficiency rates of 1,7-dimethylxanthine, acetaminophen, caffeine, cotinine, morphine, and trimethoprim were higher than $95 \%$, while those of carbamazepine, sulfamethazine, and sulfamethoxazole were lower than $22.5 \%$. Moreover, diphenhydramine and thiabendazole had negative removal efficiency rates. The removal efficiency rates of the PPCPs in As-Samra WWTP were generally consistent with those of indicator compounds reported in the literature for conventional WWTPs.
\end{abstract}

Keywords: pharmaceutical compounds; personal care products; wastewater treatment; activated sludge system; removal efficiency 


\section{Introduction}

The main sources of emerging contaminants are pharmaceuticals and personal care products (PPCPs), endocrine disrupting chemicals (EDCs), plasticisers (e.g., bisphenol-A), flame-retardants, fuel additives, and other industrial organic products [1]. PPCPs have been detected in all environmental compartments, such as water, soil, air, biota, and wastewater at concentrations ranging from sub-ng/L levels to $\mu \mathrm{g} / \mathrm{L}[2,3]$. The presence of these compounds in the environment has been shown to result in adverse ecological and health risks for the exposed biota and humans, even at very low concentrations (ng/L range) [4-6]. However, the literature indicates that the currently employed conventional wastewater treatment processes (primary and secondary) cannot not effectively eliminate all PPCPs in the raw wastewater [7-11]. Therefore, municipal wastewater treatment plants (WWTPs) are considered as a main source for the discharge of PPCPs into surface waters.

With an increase in the contamination of waterways and water supply systems from these pollutants and the greater reliance on alternative water sources such as reuse of treated wastewater, it has become apparent that there is a need for further monitoring and research on the impact of PPCPs on the environment. Recent studies conducted in Europe, USA, and Canada have showed that the reuse of wastewater effluents (treated and untreated) can result in contamination of ground and surface water resources by PPCPs $[5,12,13]$. However, the research efforts made to address this issue in low-income countries (i.e., Jordan) are still lagging behind those in developed countries due to lack of monitoring of PPCP compounds in water resources as well as lack of availability of the analytical instruments and methods needed to identify PPCPs at low concentration levels (ng/L).

Jordan is currently relying on treated wastewater as one of the main water sources for agricultural activities. About $95 \%$ of wastewater is treated, and more than $92 \%$ of treated wastewater is reused in agricultural activities, which is one of the highest percentages of reuse among the Arab countries [14]. According to a report published in 2018, there were 32 sewage WWTPs located in Jordanian cities. The estimated amount of treated wastewater discharged by these plants is about $166 \times 10^{6} \mathrm{~m}^{3}$ [15]. As-Samra Wastewater Treatment Plant (WWTP) is considered the largest wastewater treatment facility in Jordan. It is currently serving the governorates of Amman and Zarqa, where a population of over 4 million people is growing rapidly. The plant treats annually more than $118 \times 10^{6} \mathrm{~m}^{3}$ wastewater released from the Zarqa River basin and drains most of its effluent into the King Talal Dam, which provides irrigation water for most agricultural activities at Jordan Valley. The problem of emerging contaminants has not received enough attention in Jordan. There are limited studies examining the presence of PPCPs in the influent (raw wastewater) and effluent, and their removal from As-Samra WWTP. Therefore, as far as we know, this is the first study to cover this issue in Jordan.

The objective of this study was to evaluate the occurrence of PPCPs in the largest wastewater treatment plant in Jordan (As-Samra WWTP, serving the cities of Amman and Zarqa) and to determine the removal efficiency rates of the tested compounds during the summer season.

\section{Materials and Methods}

\subsection{As-Samra WWTP}

As-Samra Wastewater Treatment Plant (WWTP) is considered the largest wastewater treatment facility in Amman Zarqa Basin in Jordan. The location of the plant is shown in Figure 1. 


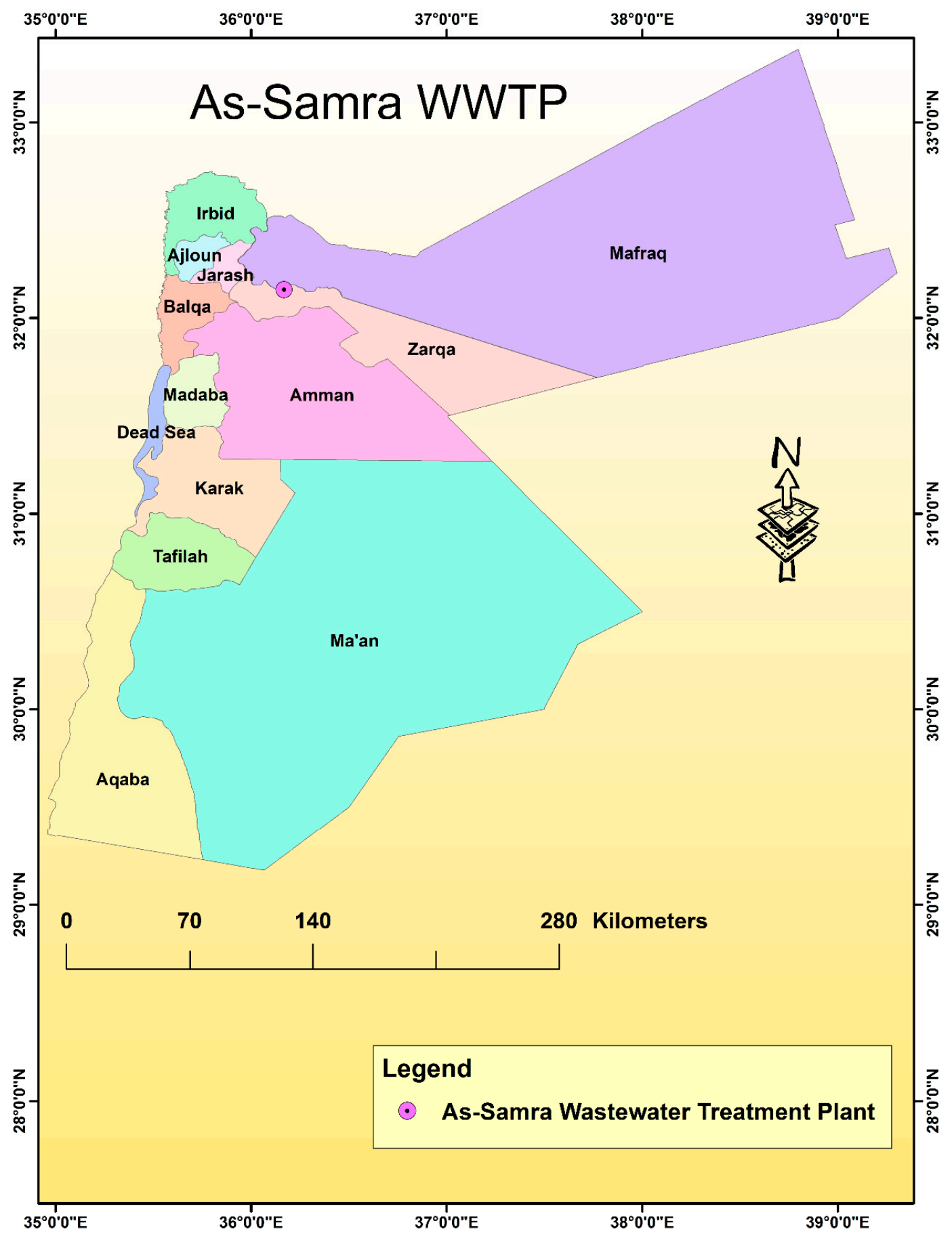

Figure 1. Location of As-Samra Wastewater Treatment Plant (WWTP).

As-Samra WWTP was established in 1986 to treat wastewater generated from Amman and Zarqa cities using wastewater stabilization ponds (WSPs). The WSPs were replaced by a new plant using an activated sludge/extended aeration system and was designed to treat an average flow of $365,000 \mathrm{~m}^{3}$ per day in 2015. The treated wastewater from As-Samra WWTP is discharged to the King Talal Dam. A schematic of the As-Samra WWTP is shown in Figure 2. The selected train included primary sedimentation, secondary activated sludge, nitrifying treatment units and disinfection by chlorination. 


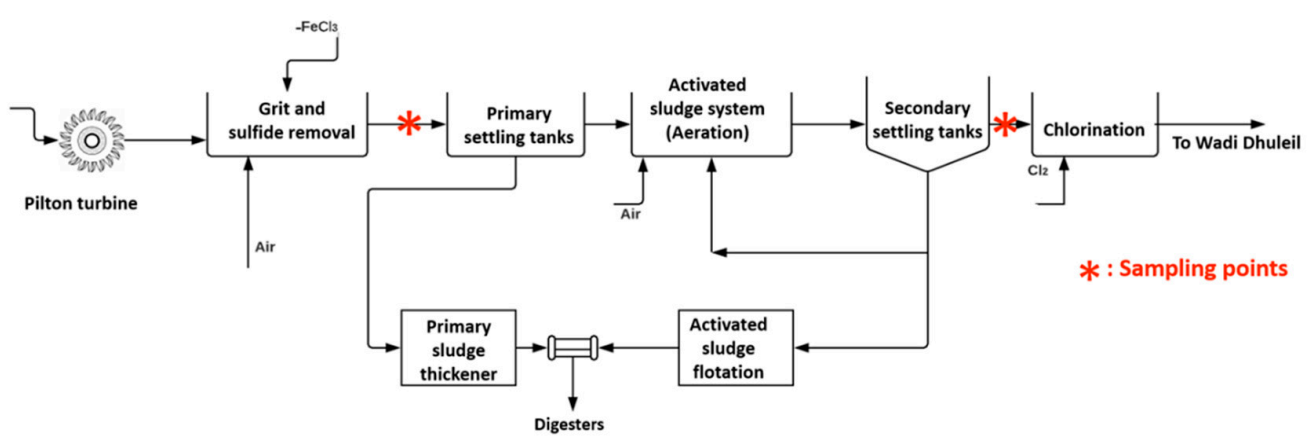

Figure 2. Process flow schematic of As-Samra WWTP and sampling points.

\subsection{Chemicals}

Reference materials, metabolites, and labeled standards were obtained from Sigma-Aldrich (St. Louis, MO, USA). The solvents used in sample preparation were of high-purity grade (OPTIMA, Fisher Scientific, St. Louis, MO, USA).

\subsection{Sample Collection, Preparation, and Extractions}

Four grab samples were collected from the influent and effluent of As-Samra WWTP in 1-L glass bottles rinsed with methanol and then washed with type I purified reagent water. All samples were stored in a refrigerator under dark conditions at 4 to $8{ }^{\circ} \mathrm{C}$. The extraction process was implemented according to the procedure provided by Water Sciences Laboratory at the University of Nebraska-Lincoln (WSL/UNL) in the United States (USA) [16]. Samples were pre-concentrated using solid phase extraction (SPE) directly or within $24 \mathrm{~h}$ after collection. The collected samples were firstly decanted to remove suspended particles and then filtered through 0.45-micron glass fiber filters using a vacuum filtration unit. A polymeric Hydrophilic-Lipophilic Balanced (HLB) Oasis 6CC cartridge (\#WAT106202, $200 \mathrm{mg}$ ) from Waters Corporation (Milford, MA, USA) was connected to a SPE manifold and vacuum pump and was preconditioned by passing $6 \mathrm{~mL}$ acetone and $6 \mathrm{~mL}$ methanol sequentially through the cartridge, followed by $6 \mathrm{~mL}$ distilled deionized water $\left(\mathrm{DDI} \mathrm{H}_{2} \mathrm{O}\right)$. The filtered sample was then pumped via tube to the cartridge using a vacuum manifold system. The sample flow through the SPE cartridge was kept at approximately $10 \mathrm{~mL} / \mathrm{min}$ or less. After the whole sample was extracted, the cartridge was rinsed with $5 \mathrm{~mL}$ of DDI $\mathrm{H}_{2} \mathrm{O}$. Room air was allowed to flow through the cartridge by continued suction for a minimum of $5 \mathrm{~min}$ to help dry the cartridge. All cartridges were labeled with the necessary information and separately stored in a clean bag at $-20{ }^{\circ} \mathrm{C}$. It is important to mention that the total number of collected samples (4) is relatively small compared with similar studies reported in the literature, which is considered a limitation in this study.

\subsection{Analytical Methods}

Sample cartridges were eluted and analyzed using liquid chromatography tandem mass spectrometry (LC-MS/MS). Cartridges were eluted with $3 \mathrm{~mL}$ of high-purity methanol into a disposable glass culture tube, followed by addition of internal standards and surrogates. The eluant volume was then reduced under a stream of nitrogen at $40{ }^{\circ} \mathrm{C}$ to a volume of $80 \mu \mathrm{L}$, and mixed with $320 \mu \mathrm{L}$ of ammonium formate added to bring the sample volume to $400 \mu \mathrm{L}$, vortexed, and then transferred to autosampler vials with silane-treated inserts. Eighteen PPCPs were measured, and their physical and chemical properties, including $\mathrm{pKa}$, Log of the octanol/water partition coefficient (Log $\mathrm{K}_{\mathrm{ow}}$ ), water solubility, and molecular weight are shown in Table 1. Sample processing and instrumentation are similar to previously published methods [16-19]. 
Table 1. Classification and physical and chemical properties of target pharmaceuticals and personal care products.

\begin{tabular}{|c|c|c|c|c|c|c|}
\hline Compound & Chemical Structure & Family and Use & pKa & $\log K_{\text {ow }}$ & $\begin{array}{c}\text { Water } \\
\text { Solubility } \\
\text { mg/L }\end{array}$ & $\begin{array}{c}\text { Molecular } \\
\text { Weight } \\
\text { g/mol }\end{array}$ \\
\hline 1,7-dimethylxanthine ${ }^{a}$ & & Stimulant & 9.9 & -0.78 & 1000 & 180.2 \\
\hline Acetaminophen ${ }^{a}$ & & Analgesic & 9.38 & 0.46 & 14,000 & 151.2 \\
\hline Amphetamine ${ }^{a}$ & & Stimulant & 10.1 & 1.76 & 28,000 & 135.2 \\
\hline Caffeine $^{\text {a }}$ & & Stimulant & 10.4 & -0.07 & 21,600 & 194.2 \\
\hline Carbamazepine $^{a}$ & & Anticonvulsant & 13.9 & 2.45 & 17.7 & 236.3 \\
\hline Cimetidine $^{\mathrm{a}}$ & & Antiacid & 6.8 & 0.40 & 9380 & 252.3 \\
\hline Cotinine $^{a}$ & & Stimulant & 4.79 & 0.07 & $1,000,000$ & 176.2 \\
\hline Diphenhydramine $^{a}$ & & Antihistamine & 8.98 & 3.27 & 3060 & 255.4 \\
\hline $\begin{array}{l}\text { Methylenedioxy amphetamine } \\
\left(\text { MDA) }{ }^{\mathrm{a}}\right.\end{array}$ & & Abuse drug & 9.67 & 1.64 & 22,500 & 179.2 \\
\hline $\begin{array}{l}\text { Methylenedioxymethamphetamine } \\
\text { (MDMA) }{ }^{a}\end{array}$ & & Abuse drug & 9.9 & 2.15 & 7034 & 193.3 \\
\hline Methamphetamine ${ }^{a}$ & & Stimulant & 9.87 & 2.07 & 13,290 & 149.2 \\
\hline Morphine $^{\mathrm{a}}$ & & $\begin{array}{l}\text { Narcotic } \\
\text { analgesic }\end{array}$ & 8.21 & 0.89 & 149 & 285.3 \\
\hline Phenazone ${ }^{a}$ & & Analgesic & 1.4 & 0.38 & 51,900 & 188.2 \\
\hline Sulfachloropyradazine ${ }^{b}$ & & Antibacterial & 5.7 & 0.31 & 8235 & 284.7 \\
\hline Sulfamethazine ${ }^{b}$ & & Antibacterial & 7.45 & 0.8 & 1500 & 278.3 \\
\hline Sulfamethoxazole ${ }^{b}$ & & Antibiotic & 6.1 & 0.48 & 3942 & 253.3 \\
\hline Thiabendazole ${ }^{b}$ & & $\begin{array}{l}\text { Fungicide and } \\
\text { parasiticide }\end{array}$ & 4.64 & 2.47 & 50 & 201.2 \\
\hline Trimethoprim $^{\mathrm{a}}$ & & Antibiotic & 7.12 & 0.91 & 400 & 290.3 \\
\hline
\end{tabular}


Compound separation was achieved on an Agilent Series 1100 HPLC system (Santa Clara, CA, USA) equipped with a Thermo-Scientific C18 embedded column $(250 \mathrm{~mm} \times 2.1 \mathrm{~mm}$, particle size $5 \mu \mathrm{m})$. The gradient method was used with $0.5 \mathrm{~g} / \mathrm{L}$ ammonium formate in water as eluent $\mathrm{A}$ and $0.5 \mathrm{~g} / \mathrm{L}$ ammonium formate in methanol as eluent $B$ in gradient elution mode at a flow rate of $0.2 \mathrm{~mL} / \mathrm{min}$. Initial mobile phase conditions were 100:0 A/B for $1 \mathrm{~min}$ followed by a linear gradient to attain a composition of $60: 40 \mathrm{~A} / \mathrm{B}$ at $10 \mathrm{~min}$, then changing to another linear gradient to reach a composition of 5:95 A/B at $18 \mathrm{~min}$. The final composition was held for $10 \mathrm{~min}$ before returning to the initial conditions. The injection volume was $20 \mu \mathrm{L}$.

Multiple reaction monitoring (MRM) was carried out on an Agilent 6410 triple-quadrupole mass spectrometer equipped with an electrospray ionization interface, using the positive-ion mode (Santa Clara, CA, USA). The conditions for the analysis were as follows: drying gas temperature, 350 ${ }^{\circ} \mathrm{C}$; capillary voltage, $4.0 \mathrm{kV}$; drying gas flow, $12 \mathrm{~L} / \mathrm{min}$; and nebulizer pressure, 40 psi. The Agilent MassHunter software was used for instrument control, data acquisition, and quantitation (Santa Clara, CA, USA).

Method detection limits were determined from the standard deviation of replicate extraction and analysis of 8 low-level $(0.015 \mu \mathrm{g} / \mathrm{L})$ fortified blanks and ranged from 0.002 to $0.050 \mu \mathrm{g} / \mathrm{L}$ with recoveries ranging from $65 \%$ to $185 \%$. Quality controls processed with cartridges included laboratory reagent blanks and laboratory fortified blanks included at a rate of $5 \%$. Surrogate recoveries ranged from $27 \%$ to $127 \%$ in sample extracts.

\section{Results}

\subsection{Operating Conditions of As-Samra WWTP}

The operating conditions were obtained from the plant and are summarized in Table 2. As-Samra WWTP has three parallel treatment trains.

The water samples for this study were collected after the grit removal unit (influent) and prior to disinfection (effluent). The average flow of As-Samra WWTP was $323,790 \mathrm{~m}^{3} /$ day during the sampling time. Moreover, the removal efficiency of WWTP for Chemical oxygen Demand (COD), Biological Oxygen Demand (BOD5), Total Suspended Solids (TSS), Total Nitrogen (T-N) and Total Phosphorus (T-P) is higher than $96 \%, 99 \%, 98 \%, 86 \%$, and $57 \%$, respectively, and the final effluent met the requirements of the Jordanian standards (JS893/2006). The wastewater characteristics and performance of the WWTP were stable across sampling events with high BOD5/COD removal. The plant treats a mixture of domestic, commercial, and industrial wastewater. In comparison with regular and similar WWTPs in other regions of USA and Europe, the WWTP in Jordan receives a higher concentration of pollutants in raw wastewater (up to $1247 \mathrm{mg} / \mathrm{L}$ of COD and up to $98 \mathrm{mg} \mathrm{T}-\mathrm{N} / \mathrm{L}$ ). This is might be caused by the low water consumption in Jordan ( $68 \mathrm{~L} /$ capita/day) as well as the discharge of industrial wastewater in the catchment of As-Samra WWTP.

Table 2. Wastewater quality and operating conditions for the influent and effluent in As-Samra WWTP during sample collection.

\begin{tabular}{|c|c|c|c|c|c|c|c|c|}
\hline $\begin{array}{l}\text { Sampling } \\
\text { Date }\end{array}$ & $\begin{array}{c}\text { Flow } \\
\text { Rate } \\
\left(\mathrm{m}^{3} / \text { day }\right)\end{array}$ & $\begin{array}{c}\text { Sampling } \\
\text { Point }\end{array}$ & $\mathrm{pH}$ & $\begin{array}{c}\text { Chemical } \\
\text { Oxygen } \\
\text { Demand } \\
\text { (COD), }(\mathrm{mg} / \mathrm{L})\end{array}$ & $\begin{array}{c}\text { Biological } \\
\text { Oxygen } \\
\text { Demand } \\
\text { (BOD5), }(\mathrm{mg} / \mathrm{L})\end{array}$ & $\begin{array}{c}\text { Total } \\
\text { Suspended } \\
\text { Solids (TSS), } \\
(\mathrm{mg} / \mathrm{L})\end{array}$ & $\begin{array}{c}\text { Total } \\
\text { Nitrogen } \\
(\mathrm{T}-\mathrm{N}),(\mathrm{mg} / \mathrm{L})\end{array}$ & $\begin{array}{c}\text { Total } \\
\text { Phosphorus } \\
\text { (T-P), (mg/L) }\end{array}$ \\
\hline 2017 & 322,246 & Effluent & 7.02 & 51.7 & 8 & 18.0 & 12.2 & 2.2 \\
\hline 6 July & 336,045 & Influent & 7.11 & 1183 & 540 & 501 & 98 & 11.3 \\
\hline
\end{tabular}

\subsection{Occurrence of PPCPs in WWTP}

The main pathway for the discharge of pharmaceuticals and personal care products (PPCPs) into area waterways is through wastewater treatment plants (WWTPs), which are inefficient in removing 
many compounds [7-11]. The results showed that 14 PPCPs were detected in the collected samples from the influent and effluent of As-Samra WWTP (Table 3). These compounds are 1,7-dimethylxanthine, amphetamine, acetaminophen, caffeine, carbamazepine, cimetidine, cotinine, diphenhydramine, MDMA, morphine, phenazone, sulfamethazine, sulfamethoxazole, thiabendazole, and trimethoprim. However, four PPCPs were below the detection limits $(<0.005 \mu \mathrm{g} / \mathrm{L})$, namely cimetidine, MDA, methamphetamine, and sulfachloropyridazine.

Table 3. Concentrations of pharmaceuticals and personal care products detected in collected grab (ppb) from As-Samra WWTP.

\begin{tabular}{|c|c|c|c|c|c|c|c|}
\hline \multirow{2}{*}{ PPCPs } & \multicolumn{2}{|c|}{$\begin{array}{c}\text { Influent Concentration } \\
\qquad(\mu \mathrm{g} / \mathrm{L})\end{array}$} & \multirow{2}{*}{$\begin{array}{c}\text { Average } \\
\text { Concentration } \\
(\mu \mathrm{g} / \mathrm{L})\end{array}$} & \multicolumn{2}{|c|}{$\begin{array}{l}\text { Effluent Concentration } \\
(\mu \mathrm{g} / \mathrm{L})\end{array}$} & \multirow{2}{*}{$\begin{array}{c}\text { Average } \\
\text { Concentration } \\
(\mu \mathrm{g} / \mathrm{L})\end{array}$} & \multirow{2}{*}{$\begin{array}{l}\text { Efficiency } \\
\text { Removal }\end{array}$} \\
\hline & $\begin{array}{l}17 \text { June } \\
2017\end{array}$ & $\begin{array}{l}6 \text { July } \\
2017\end{array}$ & & $\begin{array}{l}17 \text { June } \\
2017\end{array}$ & $\begin{array}{l}\text { 6 July } \\
2017\end{array}$ & & \\
\hline 1,7-Dimethylxanthine & 7.47 & 13.5 & 10.49 & 0.018 & 0.009 & 0.014 & 99.9 \\
\hline Acetaminophen & 28.7 & 44.7 & 36.7 & 0.038 & 0.044 & 0.041 & 99.9 \\
\hline Amphetamine & 0.005 & 0.252 & 0.129 & 0.014 & 0.037 & 0.026 & 80.2 \\
\hline Caffeine & 182.5 & 128.8 & 155.6 & 0.092 & 0.08 & 0.086 & 99.9 \\
\hline Carbamazepine & 1.54 & 0.67 & 1.104 & 0.831 & 0.881 & 0.856 & 22.5 \\
\hline Cimetidine & $<0.005$ & $<0.005$ & $<0.005$ & $<0.005$ & $<0.005$ & $<0.005$ & \\
\hline Cotinine & 4.67 & 5.29 & 4.98 & 0.030 & 0.125 & 0.078 & 98.4 \\
\hline Diphenhydramine & $<0.005$ & $<0.005$ & $<0.005$ & 0.061 & 0.026 & 0.044 & -770.0 \\
\hline MDA & $<0.005$ & $<0.005$ & $<0.005$ & $<0.005$ & $<0.005$ & $<0.005$ & 0.0 \\
\hline MDMA & 0.018 & $<0.005$ & 0.012 & $<0.005$ & $<0.005$ & $<0.005$ & 56.5 \\
\hline Methamphetamine & $<0.005$ & $<0.005$ & $<0.005$ & $<0.005$ & $<0.005$ & $<0.005$ & \\
\hline Morphine & 0.042 & 0.049 & 0.046 & $<0.005$ & $<0.005$ & $<0.005$ & 89.0 \\
\hline Phenazone & 0.042 & 0.032 & 0.037 & 0.017 & $<0.005$ & 0.011 & 70.3 \\
\hline Sulfachloropyridazine & $<0.005$ & $<0.005$ & $<0.005$ & $<0.005$ & $<0.005$ & $<0.005$ & \\
\hline Sulfamethazine & 0.021 & 0.116 & 0.069 & 0.052 & 0.034 & 0.043 & 37.2 \\
\hline Sulfamethoxazole & 0.349 & $<0.005$ & 0.177 & 0.161 & 0.031 & 0.096 & 45.8 \\
\hline Thiabendazole & 0.012 & 0.017 & 0.015 & 0.013 & 0.021 & 0.017 & -17.2 \\
\hline Trimethoprim & 0.128 & 0.213 & 0.171 & $<0.005$ & $<0.005$ & $<0.005$ & 97.1 \\
\hline
\end{tabular}

The PPCP compound with the highest estimated concentration was caffeine, followed by acetaminophen and 1,7-dimethylxanthine. This is not surprising, since all three products are available over the counter and used widely. Moreover, it is well documented in the literature that caffeine has been detected in surface water worldwide, as it is widely used in a variety of food, beverages, and drugs [22]. Caffeine had the highest concentration detected in the present study, with concentrations ranging from $128.8 \mu \mathrm{g} / \mathrm{L}$ to $182.5 \mu \mathrm{g} / \mathrm{L}$. This is consistent with some findings in the literature. Actually, caffeine is a hydrophilic compound $\left(\log \mathrm{K}_{\mathrm{ow}}=-0.07\right)$ and one the most widely detected compounds in wastewater due to the high consumption of foods, beverages, and pharmaceuticals containing this substance [23]. Moreover, Rodríguez-Gil et al. [24] reported that the highest caffeine concentrations in WWTP influents and effluents are found in the Middle East region, with concentrations almost 100 times higher than those estimated in Europe and Asia-Pacific, and 10 times higher than those estimated in North America. Like caffeine, its primary metabolite (1,7-dimetylxanthine or paraxanthine) had the third highest concentration detected in wastewater $(10.49 \mu \mathrm{g} / \mathrm{L})$. It is well known that 1,7-dimethylxanthine is generated from the human metabolite of caffeine, which exists in many products (i.e., coffee, tea, chocolate, etc.).

Acetaminophen was the second highest compound detected in the raw wastewater $(36.7 \mu \mathrm{g} / \mathrm{L})$. This could be due to the huge consumption of cough medicines and painkillers, which are also the most abused medications. Actually, acetaminophen (paracetamol) is one of the most popular and most commonly used analgesic and antipyretic drugs around the world, available without a prescription. It was discovered over 100 years ago and has been widely used in medical practice for more than half a century (since 1955). There are about 100 preparations in the market containing paracetamol alone or in combination with other active substances [25]. 


\subsection{Removal Efficiency of PPCPs in WWTP}

The results showed that the levels of PPCPs in the wastewater effluent were lower than in the raw influent, indicating that the majority of compounds can be at least partially removed by the activated sludge system used at As-Samra WWTP. Table 3 shows that the removal efficiencies vary greatly, with the lowest values $(\leq 50 \%)$ for carbamazepine, sulfamethazine, sulfamethoxazole, and thiabendazole, and the highest values (>98\%) for 1,7-dimethylxanthine, acetaminophen, caffeine, and cotinine. However, a moderate removal efficiency $(70.3 \%)$ was shown for phenazone. Previous studies have demonstrated that the removal efficiency for pharmaceutical ingredients can vary for different wastewater treatment technologies and even for a given method [26,27]. Wastewater treatments are usually divided into primary, secondary, and tertiary treatment systems [26]. The treatment process at As-Samra is considered to be a secondary wastewater treatment system. The removal efficiencies for PPCPs found in this plant were consistent with results reported for secondary treatment systems worldwide $[28,29]$. However, to improve removal, a tertiary treatment system such as advanced oxidation can remove these compounds completely, but these methods are very expensive to apply in big wastewater treatment plants [30].

The highest removal efficiencies of PPCPs were recorded for caffeine $(99.9 \%)$, acetaminophen (99.9\%), 1,7-dimethylxanthine (99.9\%), and cotinine (98.4\%). The removal efficiency of these compounds was very high $(>98.4 \%)$ among the target compounds. It is well known that physical and chemical properties of PPCPs play an important role in their transport and removal in the wastewater treatment process. A plot of removal efficiency vs. Log of the octanol/water partition coefficient ( $\left.\log \mathrm{K}_{\text {ow }}\right)$ showed a relationship for most of the compounds (R-squared $=\sim 0.71$ ), with the removal efficiency increasing as the $\log \mathrm{K}_{\mathrm{ow}}$ value decreased. For example, caffeine, 1,7-dimethylxanthine, and acetaminophen were found to be the most hydrophilic $\left(\log \mathrm{K}_{\mathrm{ow}}<1.0\right)$ and the most water soluble (water solubility $>1000 \mathrm{mg} / \mathrm{L}$ ) among the target compounds (Table 2). Therefore, due to the high water solubility and low $\log K_{\text {ow }}$, removal of these compounds by a sorption mechanism is unlikely to occur [31]. Moreover, biodegradation is considered to be a major removal mechanism for these hydrophilic compounds [32,33]. Batt et al. (2007) concluded that the removal of caffeine, among other organic micropollutants in wastewater, is dependent on a combination of biological and physicochemical treatment [34]. An efficient removal of caffeine, as that observed in the present study, has also been reported using other biological treatment systems such as slow sand filters [35].

Moreover, the results clearly showed that two PPCPs (carbamazepine and thiabendazole) were relatively unchanged after the treatment process at As-Samra WWTP. The water solubility of these compounds is very low $(17 \mathrm{mg} / \mathrm{L}$ and $50 \mathrm{mg} / \mathrm{L}$, respectively) compared with other compounds. Radjenovic et al. (2007) also reported poor biodegradability of carbamazepine in biological wastewater treatment systems (e.g., active sludge systems) [36]. The low water solubility of these compounds is believed to be an important factor of its resistance to treatment. Therefore, these compounds are used as effluent tracer compounds in the environment. In addition, the removal efficiency of thiabendazole had a negative value, which resulted from a higher concentration in the effluent than in the influent of the WWTP. Many studies have reported a negative removal efficiency for PPCPs that is caused by transformation, recombination, and/or accumulation of compounds during secondary treatment $[11,37,38]$. Moreover, As-Samra Wastewater Treatment Plant (WWTP) is the largest wastewater treatment facility in Jordan, which is located at Amman Zarqa Basin (AZB). Its annual average discharge is about $118 \times 10^{6} \mathrm{~m}^{3}$ of treated wastewater, which runs in the Zarqa river and is finally stored at King Talal Dam (KTD). A recent study showed that an analysis of the same 18 PPCPs in surface water samples at KTD revealed the persistent presence of these compounds in KTD water with the same distribution as in effluent samples from As-Samra WWTP [39]. This study suggests that it is likely that WWTPs operating in AZB watersheds do not completely remove PPCPs compounds, causing the transportation of these compounds to this important aquatic ecosystem [39]. 


\subsection{Comparison with Existing Studies}

Among all PPCPs analyzed in the current study, acetaminophen, caffeine, cotinine, and carbamazepine had the highest concentrations in the influent and effluent of As-Samra wastewater treatment plants. These concentrations were also found to be comparable with concentrations measured in domestic wastewater in India and USA (Figure 3a,b) [40,41], and higher than those reported in Greece and Vietnam [42,43]. As for acetaminophen, it is one of the medicines sold all over the world without the need for prescription. This is because of its mild effects on the human body compared to other analgesic substances (e.g., diclofenac) and its high biodegradability in the environment. Differently, caffeine is not a medicine but a stimulant that is widely consumed in stimulant drinks such as coffee and soft drinks. The concentrations of PPCPs released by WWTPs into the environment exhibit great variability, leading to inconclusive results [11]. This is mainly due to the large number of variables involved in the behavior and transport of PPCPs from their sources to the discharging point of WWTP, including fluctuations in consumption patterns, physicochemical properties of these compounds, differing conditions in WWPT plants, influent concentration in WWTPs, sewage composition, and plant operating parameters.
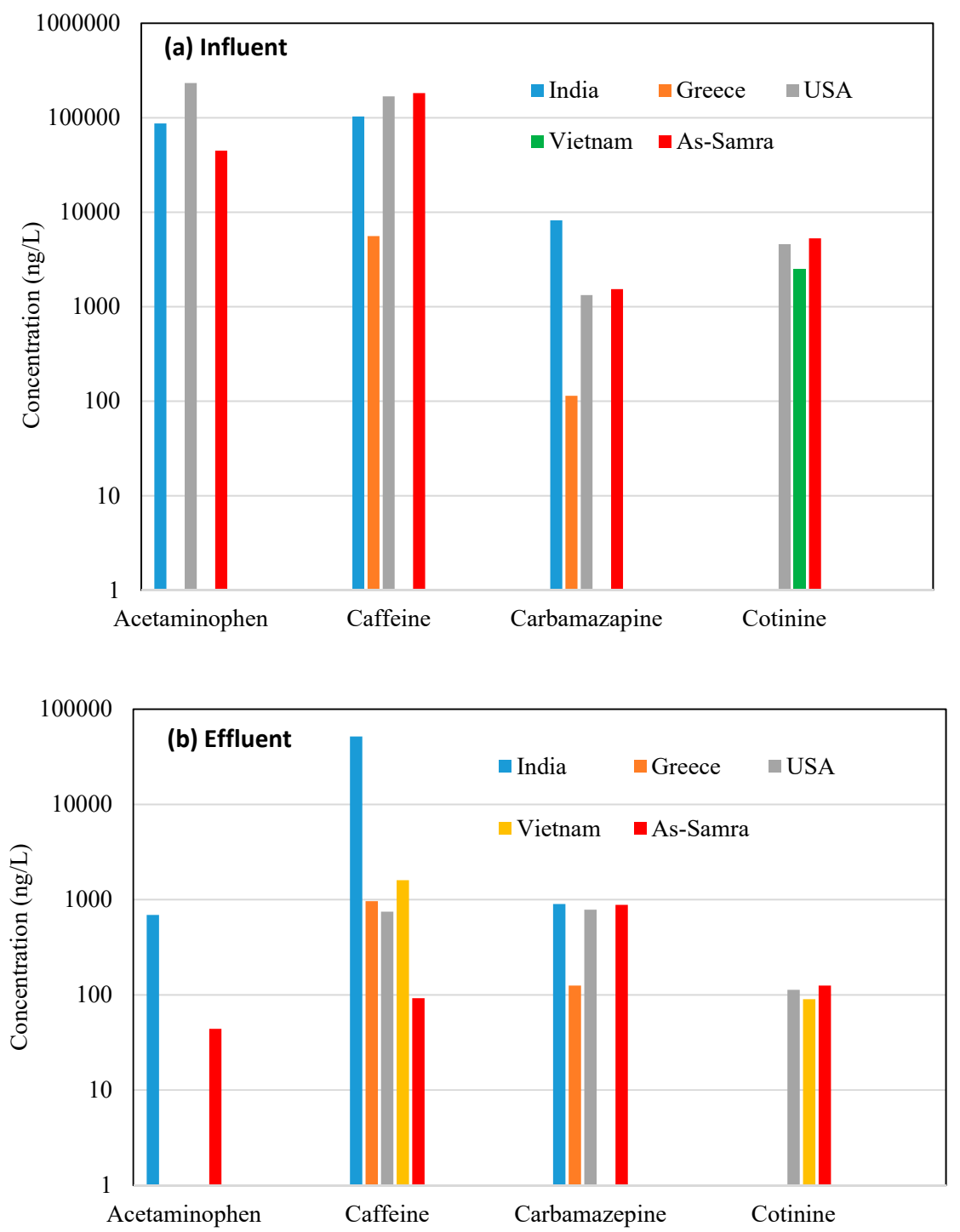

Figure 3. Concentrations of acetaminophen, caffeine, carbamazepine, and continine (ng/L) in Influent (a) and Effluent (b) of wastewater treatment plants (India, Balakrishna et al. [40]; Greece, Papageorgiou et al. [41], USA, Lubliner \& Melanie [42]; Vietnam, Nguyen et al. [43]). 
Removal efficiency rates of the PPCPs in As-Samra WWTP were generally consistent with those of indicator compounds reported in the literature for conventional WWTPs. For instance, the removal efficiency of carbamazepine observed in this study is comparable to those reported in WWTPs using an activated sludge process [9]. Moreover, many studies have reported that carbamazepine is recalcitrant in the environment and during wastewater treatment, which is mainly due to the lowest sorption and biodegradability in wastewater treatments $[44,45]$. Although data exists on the occurrence and removal of PPCPs during WWTPs worldwide (Europe, USA, Canada, and Asia), to the best of our knowledge, scarce data are currently available on the occurrence and removal of these compounds in WWTPs located in the Middle East and North Africa (MENA region). Actually, the research efforts made to address this issue in the MENA region is still lagging behind those in developed countries due to lack of monitoring of PPCP compounds in water resources as well as lack of availability of the analytical instruments and methods needed to identify PPCPs at low concentration levels (ng/L).

\section{Conclusions}

Nine PPCPS were detected in the samples collected from the influent and effluent of As-Samra WWTP, namely 1,7-dimethylxanthine, acetaminophen, caffeine, carbamazepine, cimetidine, cotinine, phenazone, sulfamethazine, sulfamethoxazole, and thiabendazole. 1,7-Dimethylxanthine, acetaminophen, and caffeine had the highest average concentrations in raw wastewater due to their high over-the-counter availability and wide use. However, the highest average concentrations detected in treated wastewater were for carbamazepine, sulfamethoxazole, caffeine, and cotinine. This study clearly showed that incomplete removal and/or degradation of PPCPs takes place in As-Samra WWTP. Therefore, a monitoring campaign should be implemented to evaluate the occurrence and removal of PPCPs in As-Samra WWTP over the four seasons. Moreover, there is a lot of scientific research and information regarding the chemistry, toxicity, and fate of pharmaceutical contaminants in wastewater treatment plants. Most of these research efforts have focused on removing these contaminants from the effluent wastewater. However, less effort has been made to minimize the levels of these contaminants at their sources, especially at home, pharmacies, and hospitals. Therefore, there is a need in Jordan to raise public awareness about the impact of these contaminants on water and the food cycle. This awareness will help the local authorities to implement any future policies that cover pharmaceutical waste management and handling at home, pharmacies, and hospitals.

Author Contributions: The idea for the study was developed by O.A.-M. and S.B.-H. O.A.-M. supervised and administrated the project. The design of the experiment method was provided by O.A.-M. and S.B.-H., D.S. carried out instrument analysis. Formal analysis, data curation, writing the paper and manuscript review were accomplished by O.A.-M., D.A., S.D., S.B.-H. and D.S.

Funding: The study was supported by the Partnership for Enhanced Engagement in Research (PEER) program administered by the National Academy of Sciences (NAS) and funded by the United States Agency for International Development (USAID), Project number: 5-91 (Cycle 5) "The occurrence and fate of pharmaceutical residues from their sources to water bodies and food chain."

Acknowledgments: We thank Ayoup Ghrair, Layal Salhi, Sakhaa Al-Naimi, and Hanan Hashim for their assistance in sample collection and preparation. Also thanks to Sathaporn Onanog and Victoria Wickham for final processing and instrumental analysis at the University of Nebraska.

Conflicts of Interest: The authors declare no conflict of interest.

\section{References}

1. Daughton, C.G. Emerging pollutants, and communicating the science of environmental chemistry and mass spectrometry: Pharmaceuticals in the environment. J. Am. Soc. Mass. Spectrom. 2001, 12, 1067-1076. [CrossRef]

2. Ternes, T.A. Occurrence of drugs in German sewage treatment plants and rivers. Water Res. 1998, 32, 3245-3260. [CrossRef]

3. Kümmerer, K. The presence of pharmaceuticals in the environment due to human use: Present knowledge and future challenges. J. Environ. Manag. 2009, 8, 2354-2358. [CrossRef] [PubMed] 
4. Bound, J.P.; Voulvoulis, N. Household Disposal of Pharmaceuticals as a Pathway for Aquatic Contamination in the United Kingdom. Environ. Health Perspect. 2005, 113, 1705-1711. [CrossRef] [PubMed]

5. Kolpin, D.W.; Furlong, E.T.M.; Meyer, T.; Thurman, E.M.; Zaugg, S.D.; Barber, L.B.; Buxton, H.T. Pharmaceuticals, hormones, and other organic wastewater contaminants in U.S. streams, 1999-2000: A national reconnaissance. Environ. Sci. Technol. 2002, 36, 1202-1211. [CrossRef] [PubMed]

6. Bunch, A.; Bernot, M. Distribution of nonprescription pharmaceuticals in central Indiana streams and effects on sediment microbial activity. Ecotoxicology 2011, 20, 97-109. [CrossRef] [PubMed]

7. Carballa, M.; Omil, F.; Lema, J.M.; Llompart, M.; García-Jares, C.; Rodríguez, I.; Gómez, M.; Ternes, T. Behavior of pharmaceuticals, cosmetics and hormones in a sewage treatment plant. Water Res. 2004, 38, 2918-2926. [CrossRef] [PubMed]

8. Jones, O.A.; Lester, J.N.; Voulvoulis, N. Pharmaceuticals: A threat to drinking water? Trends Biotechnol. 2005, 23, 163-167. [CrossRef] [PubMed]

9. Miège, C.; Choubert, J.M.; Ribeiro, L.; Eusèbe, M.; Coquery, M. Fate of pharmaceuticals and personal care products in wastewater treatment plants-Conception of a database and first results. Environ. Pollut. 2009, 157, 1721-1726. [CrossRef]

10. Monteiro, S.C.; Boxall, A.B.A. Occurrence and fate of human pharmaceuticals in the environment. Rev. Environ. Contam. Toxicol. 2010, 202, 53-154.

11. Verlicchi, P.; Al Aukidy, M.; Zambello, E. Occurrence of pharmaceutical compounds in urban wastewater: Removal, mass load and environmental risk after a secondary treatment-A review. Sci. Total Environ. 2012, 429, 123-155. [CrossRef] [PubMed]

12. Veach, A.M.; Bernot, M.J. Temporal variation of pharmaceuticals in an urban and agriculturally influenced stream. Sci. Total Environ. 2011, 409, 4553-4563. [CrossRef] [PubMed]

13. Barnes, K.K.; Kolpin, D.W.; Furlong, E.T.; Zaugg, S.D.; Meyer, M.T.; Barber, L.B. A national reconnaissance of pharmaceuticals and other organic wastewater contaminants in the United States-I) Groundwater. Sci. Total Environ. 2008, 402, 192-200. [CrossRef] [PubMed]

14. El-Ashry, M.; Saab, N.; Zeitoon, B. Water: Sustainable Management of a Scarce Resource; Annual Report of Arab Forum for Environment and Development; AFED: Beirut, Lebanon, 2010; pp. 125-136.

15. Ministry of Water and Irrigation (MWI). The Annual Report of Ministry of Water and Irrigation; MWI: Amman, Jordan, 2018.

16. Bartelt-Hunt, S.L.; Snow, D.D.; Damon, T.; Shockley, J.; Hoagland, K. The occurrence of illicit and therapeutic pharmaceuticals in wastewater effluent and surface waters in Nebraska. Environ. Pollut. 2009, 157, 786-791. [CrossRef] [PubMed]

17. Snow, D.D.; Damon-Powell, T.R.; Onanong, S.; Cassada, D.A. Sensitive and simplified analysis of natural and synthetic steroids in water and solids using on-line solid phase extraction and microwave-assisted solvent extraction coupled to liquid chromatography tandem mass spectrometry atmospheric pressure photoionization. Anal. Bioanal. Chem. 2013, 405, 1759-1771.

18. Lee, S.; Paspalof, A.; Snow, D.; Richmond, E.; Rosi-Marshall, E.; Kelly, J. Occurrence and potential biological effects of amphetamine on stream communities. Environ. Sci. Technol. 2016, 50, 9727-9735. [CrossRef] [PubMed]

19. D'Alessio, M.; Onanong, S.; Snow, D.; Ray, C. Occurrence and removal of three classes of pharmaceutical compounds at four wastewater treatment plants in Hawaii and their environmental fate. Sci. Total Environ. 2018, 631, 1360-1370. [CrossRef] [PubMed]

20. The PubChem Project. 2018. Available online: https://pubchem.ncbi.nlm.nih.gov (accessed on 11 April 2018).

21. Dı'az-Cruz, M.S.; de Alda, M.J.L.; Barcelo', D. Determination of antimicrobials in sludge from infiltration basins at two artificial recharge plants by pressurized liquid extraction-liquid chromatography-tandem mass spectrometry. J. Chromatogr. A 2006, 1130, 72-82. [CrossRef]

22. Buerge, I.J.; Poiger, T.; Muller, M.D.; Buser, H.R. Caffeine, an anthropogenic marker for wastewater contamination of surface waters. Environ. Sci. Technol. 2003, 37, 691-700. [CrossRef]

23. Díaz-Garduño, B.; Pintado-Herrera, M.G.; Biel-Maeso, M.; Rueda-Marquez, J.J.; Lara-Martín, P.A.; Perales, J.A.; Manzano, M.A.; Garrido-Perez, C.; Martín-Díaz, M.L. Environmental risk assessment of effluents as a whole emerging contaminant: Efficiency of alternative tertiary treatments for wastewater depuration. Water Res. 2017, 119, 136-149. [CrossRef] 
24. Rodríguez-Gil, J.L.; Cáceres, N.; Dafouz, R.; Valcarcel, Y. Caffeine and paraxanthine contamination in aquatic systems: Global exposure distributions and probabilistic risk assessment. Sci. Total Environ. 2018, 612, 1058-1071. [CrossRef] [PubMed]

25. Benista, M.J.; Nowak, J.Z. Paracetamol Mechanism of Action Applications and Safety Concern. Acta Pol. Pharm. 2014, 71, 11-23.

26. Greenham, R.T.; Miller, K.Y.; Tong, A. Removal efficiencies of top-used pharmaceuticals at sewage treatment plants with various technologies. J. Environ. Chem. Eng. 2019, 7, 103294. [CrossRef]

27. Comber, S.; Gardner, M.; Sörme, P.; Ellor, B. The removal of pharmaceuticals during wastewater treatment: Can it be predicted accurately? Sci. Total Environ. 2019, 676, 222-230. [CrossRef] [PubMed]

28. Rosal, R.; Rodríguez, A.; Perdigón-Melón, J.A.; Petre, A.; García-Calvo, E.; Gómez, M.J.; Agüera, A.; Fernández-Alba, A.R. Occurrence of emerging pollutants in urban wastewater and their removal through biological treatment followed by ozonation. Water Res. 2010, 44, 578-588. [CrossRef] [PubMed]

29. Lee, S.; Kim, K.; Lee, M.; Lee, B. Detection status and removal characteristics of pharmaceuticals in wastewater treatment effluent. J. Water Process. Eng. 2019, 31, 100828. [CrossRef]

30. Mehrjouei, M.; Müller, S.; Moller, D. Energy consumption of three different $€$ advanced oxidation methods for water treatment: A cost-effectiveness study. J. Clean. Prod. 2014, 65, 178-183. [CrossRef]

31. Matamoros, V.; Bayona, J.M. Elimination of pharmaceuticals and personal care products in subsurface flow constructed wetlands. Environ. Sci. Technol. 2006, 40, 5811-5816. [CrossRef]

32. Huber, C.; Bartha, B.; Harpaintner, R.; Schroder, P. Metabolism of acetaminophen (paracetamol) in plants-Two independent pathways result in the formation of a glutathione and a glucose conjugate. Environ. Sci. Pollut. Res. 2009, 16, 206-213. [CrossRef]

33. Hijosa-Valsero, M.; Matamoros, V.; Martin-Villacorta, J.; Becares, E.; Bayona, J.M. Assessment of full scale natural systems for the removal of PPCPs from wastewater in small communities. Water Res. 2010, 44, 1429-1439. [CrossRef]

34. Batt, A.L.; Kim, S.; Aga, D.S. Comparison of the occurrence of antibiotics in four full-scale wastewater treatment plants with varying designs and operations. Chemosphere 2007, 68, 428-435. [CrossRef] [PubMed]

35. D'Alessio, M.; Yoneyama, B.; Kirs, M.; Kisand, V.; Ray, C. Pharmaceutically active compounds: Their removal during slow sand filtration and their impact on slow sand filtration bacterial removal. Sci. Total Environ. 2015, 524, 124-135. [CrossRef] [PubMed]

36. Radjenovic, J.; Petrovic, M.; Barceló, D. Analysis of pharmaceuticals in wastewater and removal using a membrane bioreactor. Anal. Bioanal. Chem. 2007, 387, 1365-1377. [CrossRef] [PubMed]

37. Gao, J.; Huang, J.; Chen, W.; Wang, B.; Wang, Y.; Deng, S.; Yu, G. Fate and removal of typical pharmaceutical and personal care products in a wastewater treatment plant from Beijing: A mass balance study. Front. Environ. Sci. Eng. 2016, 10, 491-501. [CrossRef]

38. Kagle, J.; Porter, A.W.; Murdoch, R.W.; Rivera-Cancel, G.; Hay, A.G. Chapter 3 Biodegradation of Pharmaceutical and Personal Care Products. Adv. Appl. Microbiol. 2009, 67, 65-108. [CrossRef] [PubMed]

39. Al-Mashaqbeh, O.A.; Ghrair, A.M.; Alsafadi, D.; Dalahmeh, S.S.; Bartelt-Hunt, S.L.; Snow, D.D. Analysis of Some Pharmaceuticals in surface water in Jordan. In Proceedings of the WSTA 13th Gulf Water Conference, Kuwait City, Kuwait, 12-14 March 2019.

40. Balakrishna, K.; Rath, A.; Praveenkumarreddy, Y.; Guruge, K.S.; Subedi, B. A review of the occurrence of pharmaceuticals and personal care products in Indian water bodies. Ecotox. Environ. Saf. 2017, 137, 113-120. [CrossRef]

41. Papageorgiou, M.; Kosma, C.; Lambropoulou, D. Seasonal occurrence, removal, mass loading and environmental risk assessment of 55 pharmaceuticals and personal care products in a municipal wastewater treatment plant in Central Greece. Sci. Total Environ. 2016, 543, 547-569. [CrossRef]

42. Lubliner, B.; Redding, M.; Ragsdale, D. Pharmaceuticals and Personal Care Products in Municipal Wastewater and Their Removal by Nutrient Treatment Technologies; Washington State Department of Ecology: Olympia, WA, USA, 2010.

43. Nguyen, H.; Thai, P.; Kaserzon, S.; O’Brien, J.; Eaglesham, G.; Mueller, J. Assessment of drugs and personal care products biomarkers in the influent and effluent of two wastewater treatment plants in Ho Chi Minh City, Vietnam. Sci. Total Environ. 2018, 631, 469-475. [CrossRef] 
44. Onesios, K.M.; Yu, J.T.; Bouwer, E.J. Biodegradation and removal of pharmaceuticals and personal care products in treatment systems: A review. Biodegradation 2009, 20, 441-466. [CrossRef]

45. Ying, G.G.; Kookana, R.S.; Kolpin, D.W. Occurrence and removal of pharmaceutically active compounds in sewage treatment plants with different technologies. J. Environ. Monit. 2009, 11, 498-505. [CrossRef]

(C) 2019 by the authors. Licensee MDPI, Basel, Switzerland. This article is an open access article distributed under the terms and conditions of the Creative Commons Attribution (CC BY) license (http://creativecommons.org/licenses/by/4.0/). 